\title{
Slowing Economic Growth around the World in the 21st Century
}

\author{
Yitian Lyu' ${ }^{1}$, Chenrui Zhang² \\ ${ }^{1}$ Shanghai Starriver Bilingual School, Shanghai, China \\ ${ }^{2}$ The Albany Academies, Albany, USA \\ Email: yitianlv@sohu.com,809198838@qq.com
}

How to cite this paper: Lyu, Y.T. and Zhang, C.R. (2019) Slowing Economic Growth around the World in the 21st Century. Open Journal of Business and Management, 7, 1926-1935.

https://doi.org/10.4236/ojbm.2019.74131

Received: August 18, 2019

Accepted: October 9, 2019

Published: October 12, 2019

Copyright () 2019 by author(s) and Scientific Research Publishing Inc. This work is licensed under the Creative Commons Attribution-NonCommercial International License (CC BY-NC 4.0).

http://creativecommons.org/licenses/by-nc/4.0/

\begin{abstract}
When the world goes into the 21st century, there is a general and apparent trend of slowing-down for all economies around the world, especially for the super economies. In this essay, in order to derive the possible factors that lead to the slowdown, we are going to analyze the economic situation of the top four economies (China, Japan, and EU, chiefly the US). The significant factors that we find out include the less effect of capital accumulation; the decreasing fertility rate from the 1960s; the slowdown productivity; and the economic instability. Based on these factors that we have derived, we predict that the economy will keep slowing down worldwide.
\end{abstract}

\section{Keywords}

Capital Accumulation, Fertility Rate, Economic Instability, Solow Model, Globalization, Demographic Structure

\section{Introduction}

After entering the 21st century, the pace of nearly all the super economies slows down. According to the data, the most significant four super economies USA, EU, Japan, and China, all have equal or less than 10 percent of GDP as they enter the 21 st century, and some even have negative GDP growth rate for a few years. Indeed, Japan had a small and temporary negative GDP growth rate from 1998 to 2000, in 2002, and between 2008 and 2010 because of the economic recession. Moreover, the United States had a temporary negative GDP growth between 2000 and 2002, between 2008 and 2010 because of economic recession, in 2011, and in 2014. Also, the European Union had a period of negative GDP growth between 2008 and 2010 because of the general economic recession, and between 2012 and 2014. They all experienced a decrease in the GDP growth rate for $2 \%$ - 
$3 \%$ in the past 18 years [1]. This general trend of slowing down could be explained by the concept of "catch up effect": that the economies' growth rates will keep decreasing as it is growing. However, the concept itself is just explaining a fact: the real reasons for slowing down are still behind. Understanding the real factors that lead to the slowdown has high importance to everyone, not only economists. Because the world economy is directly relating to our real life. Will we become richer? Will we suffer another financial crisis? Will our next generation still be trapped in this slowdown? No one knows precisely, even if Adam Smith is still alive, but at least we can know the possible reasons. This essay analyzes the three different parts that cause the slowdown in the 21st century: the less effect of capital accumulation; the decreasing fertility rate from the 1960s; the slowdown productivity; and the economic instability. In the essay, the group analyzes data from four super economies, including China, Japan, the US, and the European Union, especially America. They together occupy around 70 percent of GDP around the world, and America is the biggest economy in the world. In the 21st century, when import, export, and financial investments, bind all the economies, a bigger economy has a more significant impact on the world. So, as $70 \%$ GDP of the world, these four economies are perfect samples to explain the slowdown and to predict how the world will act in the future. The group first discusses the less effect of capital accumulation based on the Solow model. Solow model states a negative relationship between the real output and capital accumulation. That is, when the capital is increasing at a constant rate, because of the increasing depreciation, the real output is increasing at a decreasing speed. The reason why the US has a less growth rate than China is that the US has already a considerable amount of capital accumulation while China still has a relatively low one. However, in the future, for both countries, the slowdowns are unavoidable. The second factor we find is demographic structural change. The decrease in fertility rate since 1960 in the US makes the number of retired increase faster than the number of young people who first enter the labor force. That is, there is an increasing shortage of labor in the 21st century and a higher social security burden for the US economy. The third factor is the productivity has a decreasing growth rate. Productivity is composed of technology and quality of labor. In the 21st century, the growth rate of technology is of a constant level; however, the labor quality's growth rate is decreasing. Thus, the growth rate of productivity is decreasing. Finally, the last factor is financial instability. The financial crisis of 2008 caused great loses in worldwide, and the aftermath is still affecting the world now. It is directly caused by the fraud and stupidity of a small group of people and the blind optimism atmosphere in the whole economy. Regarding the future prediction of economies, we predict that the general trend is that the GDP growth will keep slowing down in all the super economies. Moreover, the slowdown will spread out to the whole world because of the tight bonds created by imports, exports, and financial investment between all the economies [2]. 


\section{Data and Methods}

Figure 1 shows the change in the percentage rate of capital per capita in the US from 2005 to 2018 . The general trend for this one is relatively stable. However, in the period from 2008 to 2010, the percentage change for capital per capita decreased: starting in 2008, the trend shows a continuous decrease until 2010. Then, after 2010, the rate recovered and became stable again.

Figure 2 shows that China has a different trend of economic growth compared to the other three countries. China has a higher rate of economic growth than those of the other three. In the graph, the other three countries experienced a recession in 2009, but China did not. After the recession, all those four countries (representatives of the whole world) recovered, and the rate became relatively stable again.

Figure 3 shows a generally decreasing trend about the birth rate in the period of 1960 to 2018 in the US. The number of new-born babies every 1000 Americans was decreasing and reached the bottom in the year 2018. This tendency might have some degrees of influence on the age structure and the working population, leading to some effects on the whole US economy.

Figure 4 shows a decreasing growth rate of the civilian labor force from 2000 to 2018 . The growth rate decreases from $2.3 \%$ to a relatively stable level of about $1.0 \%$ from 2000 to 2018 (except for the financial crisis period.)

Figure 5 shows how the percentage change in revenue earned by using technology in the US. It implies the benefits that technology has brought us. Except for the year 2009 shows a negative percentage change, all other years show a positive stable trend that is around $5 \%$ to $6 \%[3]$.

The methods used in the research are that the group get the graphs about changes on different factors of the world economies, such as the percentage change in GDP of the world, change in real GDP of the sample countries, change in number of births in the US, percentage change in civilian labor force, and



Figure 1. Percentage change in capital per capita from 2005 to 2018. 


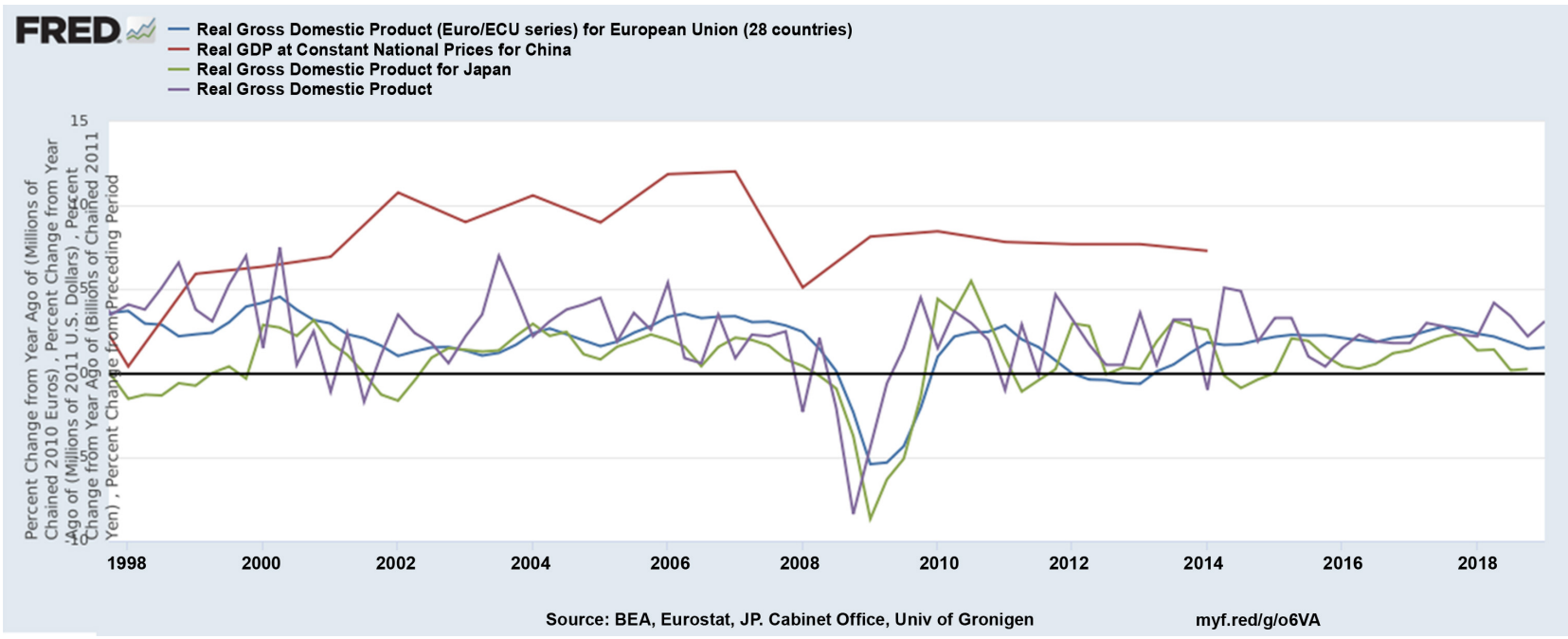

Figure 2. Percentage change in real GDP in the EU, Japan, China, and the US from 1998 to 2018.

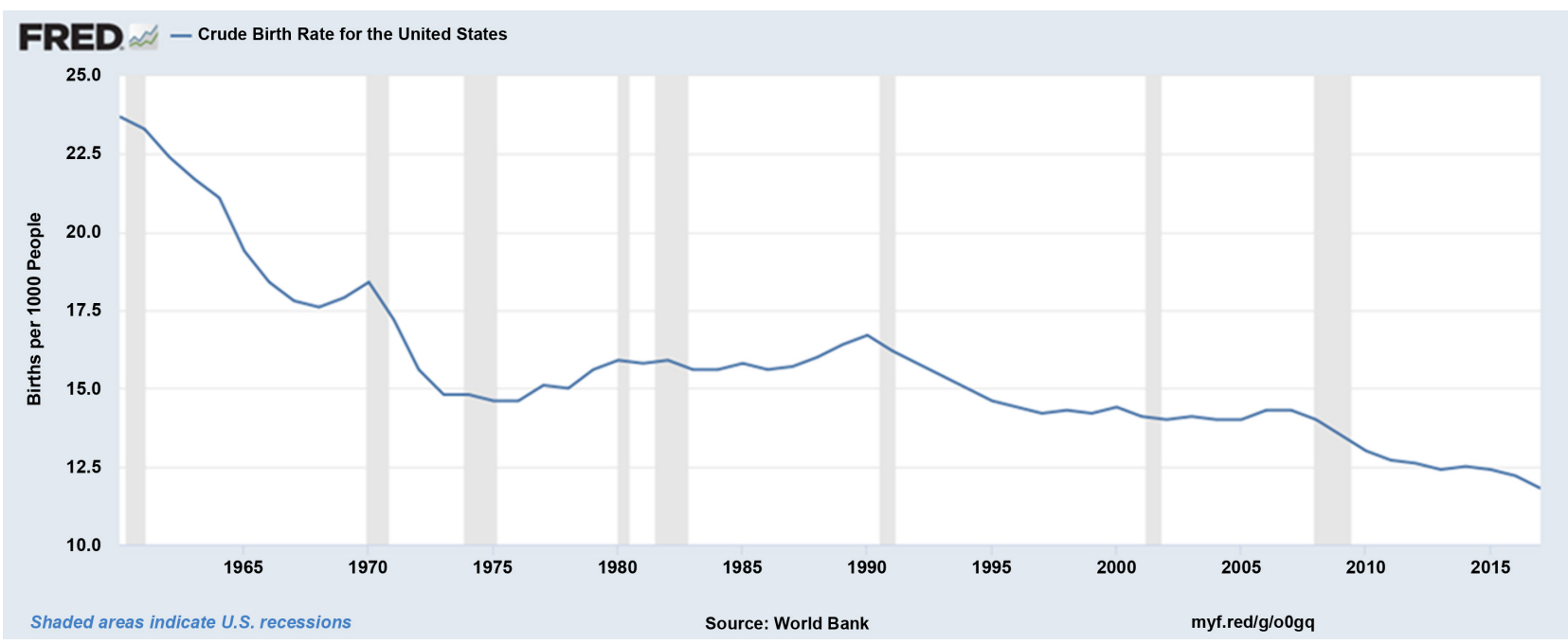

Figure 3. Change in the number of births per 1000 people in the US from 1960 to 2018.

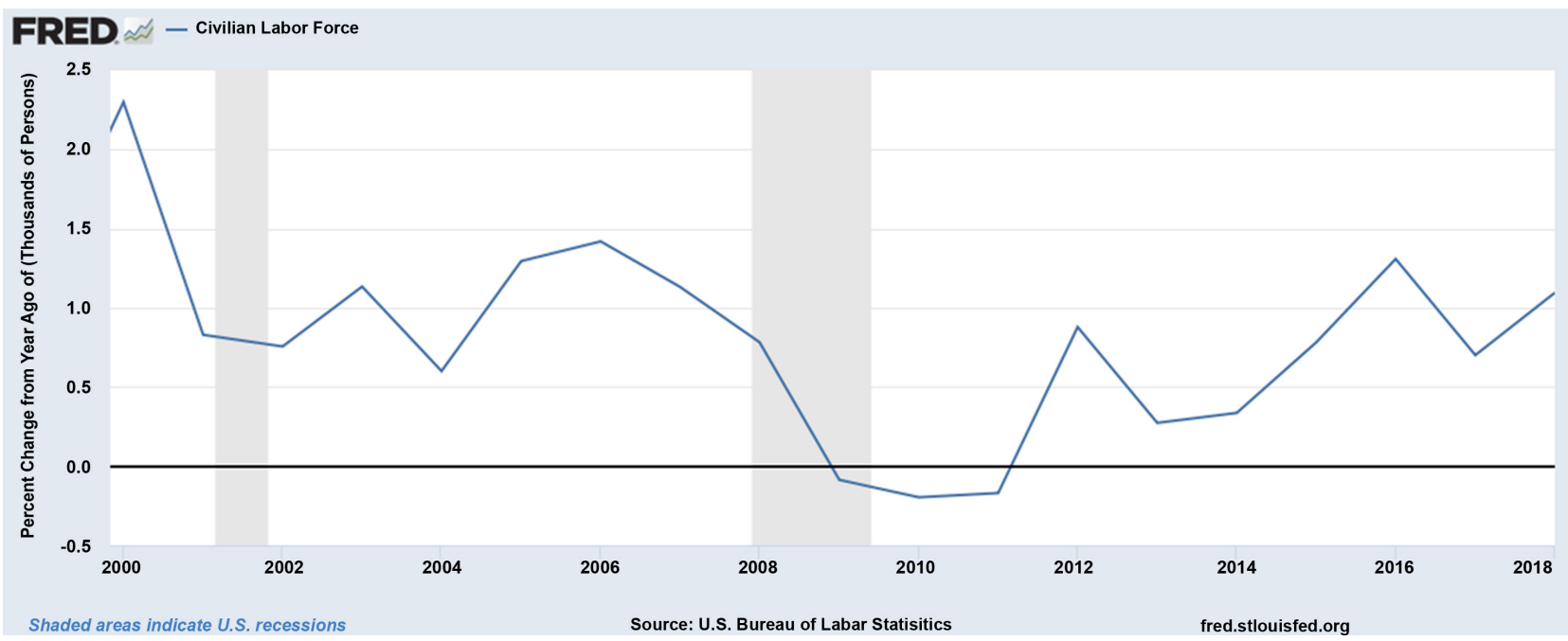

Figure 4. Percentage change of civilian labor force from 2000 to 2018. 


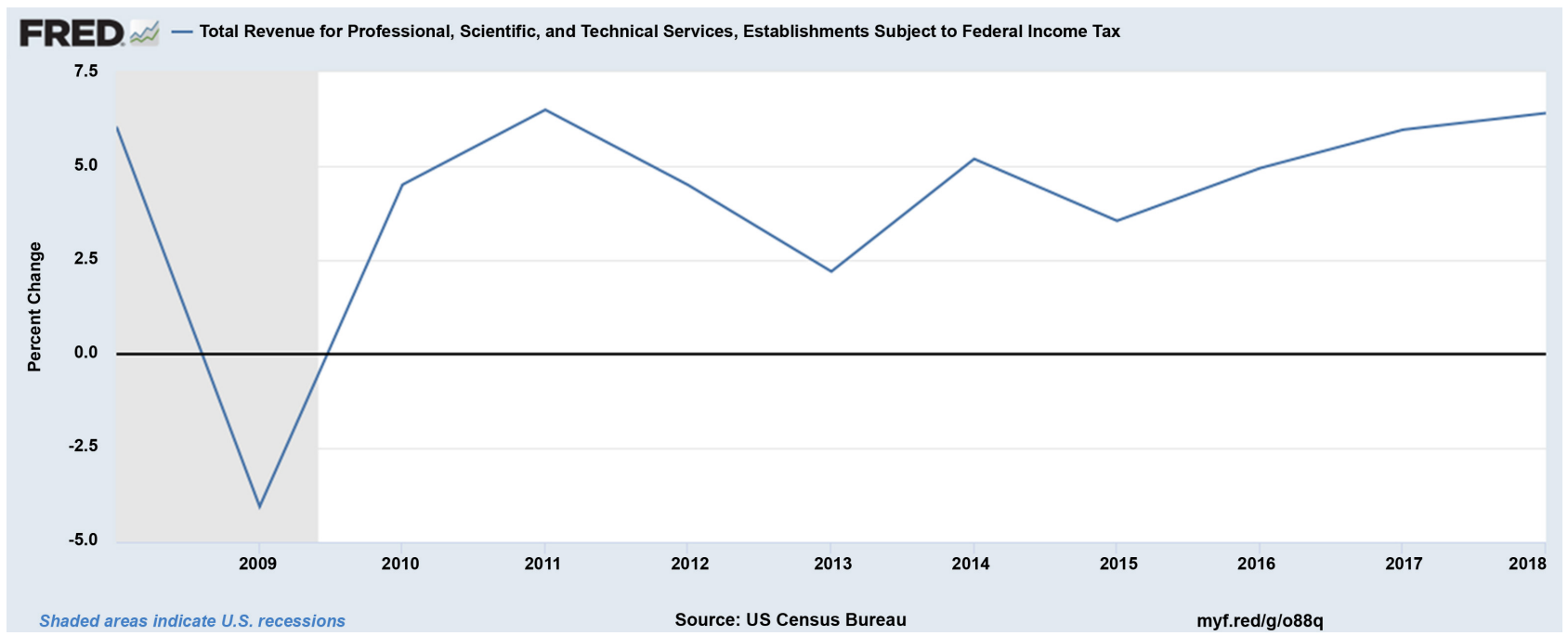

Figure 5. Percentage change in the revenue earned by technology in the US from 2008 to 2018.

percentage change in the revenue gained by technology in the US. Then the group analyzes the statics from these graphs and derives a general trend of the changes. Finally, the group attempts to provide possible explanations or implications for these economic phenomena, which can help them to predict the future behaviors of the world economies.

\section{Analysis}

As we have stated in the introduction part, according to the data, the most significant four economies USA, EU, Japan, and China, all have equal or less than 10 percent of GDP as they enter the 21st century, and some even have negative GDP growth rate for a few years. They experienced a simultaneous decrease in the GDP growth rate for $2 \%-3 \%$ in the past 18 years. In this part, we are going to analyze the four main factors that lead to the slow down: the less effect of capital accumulation; the demographical change; the constant-increasing productivity; and the economic instability. We are going to use the US as samples to show these factors since the US is the most robust economy in the world.

Firstly, according to Robert Solow, the capital per capita determines the total output of a country. The formula $Y=A K^{\nmid \alpha)} \times L^{(1-\alpha)}$ shows a homodromous relationship between the capital per capita and GDP. In history, the significant economic breakthroughs are all accompanied by the booming of capital per capita. However, the relationship between GDP and capital per capita is not constant. An increase in capital will lead to an increase in depreciation which makes the capital less effective. Suppose the economy has a constant amount of investment growth, at first it will face a rapid growth rate of output. However, as the amount of investment keeps growing, the depreciation also increases; thus, after a period of economic booming, the growth rate of the economy gradually slows down. Eventually, when the amount of increase in investment equals the depreciation, the economy will stop growing [4]. 
According to the data, America generally has a stable increase in the capital per capita (except for the great recession period) during the 2001-2007 and 2010-2018. However, the US, as all the developed economy, has experienced the rapid growth period in the past 200 years. The accumulation of capital no longer contributes to the growth of output that much. With a constant rate of investment growth, the US's growth rate faces a continuous decrease. That is one main reason why the US's growth rate decreased from 5\% in 2001 to about $3 \%$ in 2018. In comparison, among all the super economies, China is still in the stage of developing rather than developed. In this period, China could gain higher retribution from the same amount of increase in investment. That is the reason why China could maintain a growth rate higher than 7\% during 2001-2007 and 2010-2018 [5].

Secondly, the population is another determinant of the total output. Before 1800, the total population on the earth is almost constant. According to the Malthusian model, the limited population is because of the limited resource. With a limited population, the total output is also limited. However, after the first industrial revolution, the advanced steam engine largely improved the efficiency of using the resource. Thus, after the industrial revolution, the population is no longer bounded by the old limit in the Malthusian era. People's ideology and influential events such as wars become the main factors that affect the total population. The total population, today in the 21 st century, is decided by the ideology of the last generation from 1950 to 1990.

According to the data, the fertility rate in the US decreases since 1960 (3.6540) and reaches the lowest point in 1976 (1.7380); after 1976 the fertility rate remains the level at two births per women. The decreasing fertility rate shows that the US has decreasing population growth. Indeed, in the Solow model, lower population means higher capital per capita [6]. However, the slowing-down population growth leads to a bigger problem-a shortage of labor. The plummet of fertility rate occurred in 1960. The babies born in 1960 are now 68 years old, and their retiring age is 67 years old, which means the decreasing fertility rate results in a massive change in the population structure in the US. The percentage increase in the population of retired workers is larger than the increase in the population that becomes a labor force. Thus, the growth of the labor force in the US is decreasing, and it will last for decades. According to data (Figure 4), the growth rate of the civilian labor force has decreased from $2.3 \%$ to about $1 \%$ in the past 18 years. Besides the fertility rate, the increased life expectancy, and the increased education level also shift the population structure. Because of the development of medical technology, the life expectancy in the US increases for five more years from 1960 to 2017. Babies born in 1960 are expected to live 69.993 years while people now are expected to live 78.53 years. In the US, society has more and the elderly population. As a result, the national pension and all types of insurance will also increase. As more and more resources are consumed on the health sector by the elder, the rest of society faces a lower capital per capita, 
and thus, the growth rate slows down. Not only the US faces this problem caused by structural change in the population, the problems of the rest three countries are only more severe. Especially in China, the population more than 60 years old nearly occupies one-sixth of the total population. After enjoying the demographic dividend, countries will eventually experience the side effect-an unbalanced population structure and a slow-down in growth rate [7].

Thirdly, productivity determines the efficiency of using the resources, and it could affect the total output the most. The productivity could be separately measured by two parts: the quality of labors and the technology level. Leaps in technology level essentially cause the first and second industrial revolutions. The education standard of the labor could measure the quality of labor, and it often correlates with the advance in technology. Technology compared to labor quality is more prerequisite and could cause a more drastic change. For example, before the human invented the first computer, there was not a class in university that taught about programming. The quality of labor enhanced the progress of technology and brought achievement in technology into growth in output. In the 21 st century, human has accomplished great achievement in technology; the period of the next major technological breakthrough is shortened. From the invention of the smartphone to gene editing and artificial intelligence soon, the development in technology ensures the considerable potential economic growth in the future. According to the data, the US revenue gain from technology remains stable at $5 \%$ of the total revenue in the past eight years [8]. That means the technology development in the past eight years is also very stable. The technology development these years could not act as how the steam engine nor the internet, which ignited a whole era. We are not sure whether there will be a new revolution brought by new technology such as artificial intelligence, but, at least, the data proves that the technologies are not groundbreaking.

However, the increasing trend in labor quality slows down. Direct statistics could not tell this slowdown, so it is often ignored. While technology is stretching farther and farther, there are more and more jobs been replaced. For example, the robots replaced the workers in the factories. In this case, when the workers are no longer needed, their skills will have no value. Thus, the quality of labor decreases. The workers must reeducate themselves to regain their labor quality. That is an example of how technology decreases the quality of labor. The advanced technologies also make the period of improving labor quality longer. For example, in 1600, it would double a person's labor quality if he/she learned to write; however, in the 21 st century, it requires a person to learn to program to double his/her labor quality. It is harder and harder to improve our labor quality nowadays.

Putting the two elements together again, we could find out that there is a constant growth rate in technology but a decreasing growth rate in labor quality in the US As a result, the growth rate of productivity decreases. The decrease will last unless there is a groundbreaking technology that could lead to another revolution. 
The final factor is financial instability. As we can see in nearly all the graphs, there are plummets in 2008 in all the aspects. That is because of the financial crisis in 2008. "When the dust settled from collapse, 5 trillion dollars in pension money, real estate value, $401 \mathrm{k}$, savings, and bond has disappeared. Eight million people lost their jobs, 6 million lost their homes. And that was just in American." (from the lines in The Big Shot). In the world, nearly all the economies suffered great losses in growth rate and took years to recover. Compared to the three factors mentioned above, this factor is the most destructive one. In a macro view, this crisis is caused by an over-optimism atmosphere in the whole economy. However, in a micro view, it is directly caused by the fraud and stupidity of the wall street guys and even the government. Before the crisis, junk bonds with a B value are mixed with these of A value and sold to people as AAA bonds. And the government did nothing to stop this. After the 2008 financial crisis, fraud and stupidity do not stop. How to avoid another financial crisis should be the most crucial task for all the government.

One of the purposes of our forecasting is to point out the general trend of future economic growth for the world which could be used by investors and policy makers to evaluate and make their decisions of where to put the money and regulations on. Another purpose is that the forecasting serves as a representation of the explanations we have for the above data and analysis and it also strengthens and supports our conclusion.

\section{Forecasting}

What about the Super economies? Based on the data and the analysis, those three countries (Japan, EU, and the US) have shown a trend of decreasing economic growth. The slowdown is attributed to four reasons mentioned in the analysis part: the less effect of capital accumulation; the decreasing fertility rate from the 1960s; the slowdown productivity; and the economic instability. We could see their impacts on the US, and they are happening at the same time on the other super economies. The less effect of capital is unavoidable; the demographic structure change would cost a generation to retain an increase in the growth rate, and the growth rate of labor quality is decreasing. As a result, unless there is a new groundbreaking technology been invented, those super economies will still face a continuous slowdown in the future.

What about developing economies? As we have mentioned above in the introduction, in the 21st century, all the economies in the world are closely related because of the role of import-export and financial investment. For the developing economies, what behind their increasing growth rate are the export to those super economies and the financial investment from them? For example, the manufactory industry in Vietnam is almost constructed by foreign investment, and they also serve for foreign demand. Once the economy of those super economies slows down, there will be less import and less capital outflow. For the developing countries, they will no longer have such exports and financial in- 
vestment, and thus their economies will also slow down.

Also, for developing economies, financial instability is high. As they are developing at high speed, people's expectation would easily go over the real situation, and bubbles are easily created. The larger the bubble is, the more destructive the crisis will be. Just as the crisis in Thailand and Venezuela, the economy will not keep a high growth rate without a crisis. And how to eliminate the crisis depends on their governments.

\section{Conclusion}

In general, the four economies discussed above including China, the US, Japan, and the European Union almost all have less than 10 percent growth rate at the beginning of the 21st century, with a sharp decrease of about 3 percent in the past 20 years. The reasons include the less effect of capital accumulation; the decreasing fertility rate from the 1960s; the slowdown productivity; and the economic instability. Regarding the forecast for the future, the group predicts that in the next few decades for super economies. At the same time, the developing economies will also keep slowing down because the effect of globalization: imports and investment from super economies will decrease. They will also face a high risk of the financial crisis. As for future researches, we are carrying on an analysis of the economies of China and India for the reason behind their high growth rate and their future. The future study should also be informed that there is deficiency in this article. The deficiency includes the fact that the group researches the economies of three developed countries but only one developing country which is China so there might not be enough representatives for the developing countries to conclude things. Also, the article lacks the discussion and data from any economies in Africa and the Middle East but countries in that area are also influential to the global economy. Besides, the data collected, and the calculation involved may involve probable error and inaccuracy so the evaluations of the current situation and future predictions are a little imperfect.

\section{Acknowledgements}

We are writing here to thank several other contributors to this paper. We sincerely appreciate Professor Pablo A. Guerron from Boston College for his general guidance and advice to our paper. Also, we want to thank Yujun Song from Shanghai Linke International High School for his writing about the analysis part as well as Jinghui $\mathrm{Yu}$ for monitoring the process of writing this paper. Thank you all for helping us!

\section{Conflicts of Interest}

The authors declare no conflicts of interest regarding the publication of this paper.

\section{References}

[1] World Bank (2019) World Economic Prospects. 
http://www.worldbank.org/en/publication/global-economic-prospects

[2] Global Economic Prospects (2019).

http://www.worldbank.org/en/publication/global-economic-prospects

[3] Federal Reserve Economic Data |FRED | St. Louis Fed. (2019). https://fred.stlouisfed.org/

[4] Weil, D.N. (2009) Economic Growth. 3rd Edition, Pearson Addison Wesley, Boston.

[5] World Bank (2019) Constant GDP per Capita for the World [NYGDPPCAPKDWLD]. Retrieved from FRED, Federal Reserve Bank of St. Louis. https://fred.stlouisfed.org/series/NYGDPPCAPKDWLD

[6] World Bank (2019) Fertility Rate, Total for the United States [SPDYNTFRTINUSA]. Retrieved from FRED, Federal Reserve Bank of St. Louis. https://fred.stlouisfed.org/series/SPDYNTFRTINUSA

[7] US Bureau of Labor Statistics (2019) Civilian Labor Force [CLF16OV]. Retrieved from FRED, Federal Reserve Bank of St. Louis. https://fred.stlouisfed.org/series/CLF16OV

[8] US Census Bureau (2019) Sources of Revenue: Information Technology (IT) Infrastructure and Network Management for Computer Systems Design and Related Services, All Establishments, Employer Firms [REVINMEF5415ALLEST]. Retrieved from FRED, Federal Reserve Bank of St. Louis.

https://fred.stlouisfed.org/series/REVINMEF5415ALLEST 